\title{
Oxidative Cascade Prognosis, Antioxidants \& Selected Trace Elements in COVID-19
}

\author{
Rizwan Ahmad Ansari ${ }^{*}$, Karimah Mohammed Rabiu² \\ ${ }^{1}$ Department of Biochemistry, Yobe State University, Damaturu, Nigeria \\ ${ }^{2}$ Department of Biological Sciences, Yobe State University, Damaturu, Nigeria \\ Email: *sirna786@gmail.com
}

How to cite this paper: Ansari, R.A. and Rabiu, K.M. (2020) Oxidative Cascade Prognosis, Antioxidants \& Selected Trace Elements in COVID-19. Open Journal of Applied Sciences, 10, 688-700.

https://doi.org/10.4236/ojapps.2020.1011048

Received: September 28, 2020

Accepted: November 10, 2020

Published: November 13, 2020

Copyright () 2020 by author(s) and Scientific Research Publishing Inc. This work is licensed under the Creative Commons Attribution International License (CC BY 4.0).

http://creativecommons.org/licenses/by/4.0/ (c) (i) Open Access

\begin{abstract}
COVID-19 pandemic has now become a challenging global public health concern, having higher risk of developing fatal respiratory disease due to severe inflammatory responses associated with the virus-mediated oxidative stress. The respiratory system is most preferred target organ for this novel virus as the lung is well oxygenated and having large surface area available to the virus for exposure and successively augmenting the health complications. Oxidative stress (OS) is an important factor causing metabolic and physiological alteration and various disease augmentations within the body. Respiratory viral infection has general consociation with cytokine production, inflammation, cell death and other pathophysiological processes which may be the result of perturbed redox balance. Apart from this, the presence of conditions likes aging, diabetes and hypertension and chronic obstructive pulmonary diseases (COPD) are the risk factor for making severity of such infection outcome. It has been well established that an overproduction of reactive oxygen species (ROS) and antioxidant mechanisms deprivation are vital step for viral replica production and consequent release of pro-inflammatory cytokines is also an important factor of the innate immune responses to the pathogens that may result into acute lung damage. Additionally, ROS can damage various vital biological molecules and inactivation of essential enzymes. Oxidative stress is an important factor causing metabolic and other pathophysiological alterations, such as protein oxidations and various associated diseases. Therefore, in this paper, the significant adverse impact of virus on host cell and underlying possible biochemical mechanism has been discussed.
\end{abstract}

\section{Keywords}

COVID-19, COPD, ROS, Oxidative Stress, Cytokines, Inflammation 


\section{Introduction}

Serious health issues and deaths associated from novel COVID-19 pandemic are now global public health concern originated from China in 2019. Corona virus is single stranded RNA virus that affects the respiratory system in human. Such notorious viruses exploit the host defense mechanism in various ways for their replication and infections [1] [2]. There is a key role of an imbalance of the redox cascade conditions during viral infections [3]. Lung inflammation is the main target organ as respiratory disorder at severe stage of such respiratory viral infections is, in general, associated with the impaired redox homeostasis or oxidative stress (OS). Inflammation is an important protective phenomenon responsible to cellular or tissue damage. The main function of this process is to destroy and remove the harmful agent and damaged tissues, therefore enhancing tissue repair. Whenever this vital and normally beneficial response takes place in an uncontrolled way, the result is extreme cellular or tissue damage that comes out in the form of chronic inflammation and destruction of normal tissue. Many pro-oxidants such as the superoxide anion one of the important reactive oxygen species (ROS), generated by phagocytes deployed to sites of inflammation, are proposed to be a major cause of the cell and tissue damage, comprising apoptosis, associated with many chronic inflammatory diseases [4] [5]. Alveolar epithelial type II cells present in lung cells, in particular, are highly susceptible to the injurious effects of oxidants. The primary site of influenza virus infection in mammals includes pseudostratified, ciliated, columnar epithelium of the upper respiratory tract [6]. Influenza virus infection of the pulmonary mucosa could have important influence on airway functions, and, this mechanism is still merely understood. The cytopathology of replicating influenza virus in the airway epithelium can disrupt normal cellular architecture and morphology. After entering the host cell through any mucosa, the virus will undergo significant changes such as fusion, endocytosis and cytolysis, which will cause new virions to enter the host cell, resulting in the release of a large amount of pro-inflammatory cytokines and the change of cellular redox status.

\section{Viral Infection and Perturbed Redox State}

Oxidative deterioration of biomolecules like lipids, proteins, and DNA [7] has been reported since long time. The reactive intermediates include the superoxide anion $\left(\mathrm{O}_{2}^{-}\right)$, hydrogen peroxide $\left(\mathrm{H}_{2} \mathrm{O}_{2}\right)$, and hydroxyl radicals $(\mathrm{OH})$ all are referred as reactive oxygen species (ROS) and very reactive in nature. Each ROS has been shown to have different inherent chemical properties, which guiding its reactivity and most favored biological targets. It has been observed for $\mathrm{H}_{2} \mathrm{O}_{2}$ that can regulate the signaling pathway by oxidizing thiols moiety within proteins [8]. There are many enzymes that can bring back this oxidation to return the protein to their natural reduced state. This is very similar to the process of phosphorylation and dephosphorylation-dependent signaling pathway very common in redox biology. The levels of $\mathrm{H}_{2} \mathrm{O}_{2}$ involved with signaling cascade 
may range from picomolar to nanomolar concentration and the higher concentration may cause proteins to be inactive by hyperoxidizing thiols moiety the concerned protein [9]. Redox signaling brings up the thiol oxidation-dependent signaling changes, whereas oxidative stress refers to damage of lipids, proteins, and DNA or disruption of thiol-dependent signaling and inactivation of essential enzymes.

There is undoubted report available showing that oxidative stress is almost inevitably associated with various toxicities, the first phenomenon in many diseases that may results into multi organ failure and death. The imbalance between reactive oxygen species (ROS) production and their effective removal by antioxidants and ROS scavengers has been in consideration since long to contribute many pathological conditions for critical illnesses such as acute respiratory distress syndrome (ARDS), pulmonary fibrosis, sepsis and many others. Thus, oxidative stress has drawn much arousing interest as therapeutic target in critical illness, and antioxidants have been tested in critically ill patients for decades. It is also important to mention that ROS serve as crucial signaling molecules for cell homeostasis and adaptation to the various cellular stress such hypoxia and many others, processes that may be related to perturbed mechanism of antioxidants system [10].

Furthermore, Oxidative stress has been found to be implicative in several diseases such as diabetes and cardiovascular disease. Recent evidence has shown that ROS can play an important role as secondary messengers in signal transduction pathways [11] [12]. Cell has been equipped with a number of many enzymes like catalase, glutathione peroxidases, thioredoxin reductase, and superoxide dismutase available to overcome the oxidative stress conditions. These include. The cell also possesses a variety of lower molecular weight molecules such as tripeptide glutathione (GSH) that can counteract the harmful effects of ROS. Glutathione is present at very low concentration (millimolar) in the cell [13], is an important in detoxification pathways via glutathione transferases enzyme systems [14], and is vital for sustaining the redox potential of the cell. It is now well understood that the redox potential of the cell can regulate the activation of many genes through triggering the transcription factors including nuclear factor (NF- $\mathrm{kB})$ and activator protein (AP-1) that are important for immune function [15] [16], antioxidant defense [17], and induction of apoptosis [18] [19].

\section{Interferons and Chemokines Generation in Response to Oxidative Stress}

More recently, it has been well established that the level of oxidative stress is also very vital factor for the immune responses to viruses. Both types of immunity (innate and acquired) are required to fight any viral infection, responsible for morbidity and mortality in critically ill patients suffering from diseases. It has been reported in one of the finding during in vitro and in vivo study that Den- 
gue virus infections are the cause of generation of many inflammatory cytokines [20] and alteration in redox state increases the disease severity [21].

In response to oxidative stress, lung cells have been found to liberate many inflammatory mediators and cytokines/ chemokines such as tumour necrosis factor-a (TNF-a), interleukin (IL)-1 and IL-8. The release of chemokines induces neutrophil deployment and stimulating the activity of key transcription factors such as NF-kB and AP-1, thereby augmenting the inflammatory response and severe tissue injury [22] [23]. As a result, the acute and chronic alveolar or bronchial inflammatory response is the basic mechanism involved in the pathogenesis of many lung diseases such as asthma, chronic obstructive pulmonary disease (COPD), acute respiratory distress syndrome (ARDS), idiopathic pulmonary fibrosis (IPF) and cystic fibrosis (CF). The target place and specific characteristics of the inflammatory responses may vary in each of those early mentioned diseases, but all are characterized by the recruitment to the lungs and activation of inflammatory cells resulting to an oxidant/antioxidant imbalance.

\section{Glutathione (GSH) against Inflammatory Responses}

In one of the study it has been observed that when whole blood culture of HIV positive individual infected with Mycobacterium tuberculosis, there was an increased release of inflammatory mediator cytokines such as IL-1, TNF- $\alpha$, IL-6. However, there was interesting finding was reported in reduction of these proinflammatory cytokines (IL-1, TNF- $\alpha$, and IL-6) when whole blood culture was supplemented with GSH precursor N-acetyl cysteine (NAC) [24]. High levels of such pro-inflammatory cytokines may have detrimental effect to the host because it may result to augmentation of fever, cachexia, hemorrhagic necrosis, and lethal shock [25] [26] [27]. Furthermore, the macrophage activity may be affected with the increased level of proinflammatory cytokine like IL- 6 and may be deleterious to the host cell.

The mechanisms by which pro-inflammatory cytokines decrease intracellular GSH may be in response to increased levels of free radicals. It has been observed that increases in pro-inflammatory cytokines and an increase of free radicals are proportionally correlated which is targeted by free GSH responsible for counteracting the adverse effects in host cells. In individuals positive for HIV, there is large number production of pro-inflammatory cytokines, which results into decrease in GSH because the antioxidant is being depleted as it is involved in scavenging free radicals. Furthermore, increased number of IL-1 may also participate in reducing the intracellular GSH as it is accepted that IL-1 fasten the process of depletion of intracellular cysteine thus decreasing GSH generation and decreasing levels of GSH [28].

Human subjects infected with the HIV have shown to have lower levels of GSH in their macrophages, NK and T cells compared to individuals [29] [30] [31]. It has been reported the contribution of GSH to be involved through different mechanism to enhance the functions of $\mathrm{NK}$ and $\mathrm{T}$ cells, acts as an anti- 
oxidant and reduces the levels of pro-inflammatory cytokines (IL-1, TNF- $\alpha$, and IL-6) [25] [32] [33] [34]. Therefore, GSH has been shown to play crucial role in directly controlling bacterial infection as well as improving host defenses making functional immune cells and rejuvenating macrophage function by reducing IL-6 [24] [35]. The effects of GSH were reported to improve the control of intracellular bacterial infection when immune cells from retroviral subjects were treated with GSH-enhancing precursor like $\mathrm{N}$-acetyl cystein.

\section{Role of GSH in Immune Responses}

In the redox state counter balance, GSH is found to be key intracellular antioxidant that exerts an efficient protection against ROS, through the thiol group of its cysteine where oxidation (GSSG) and reduction (GSH) takes place by the enzyme glutathione reductase. Moreover, it has also important role in cellular signaling processes and the mechanism comprising innate immune responses to viruses [36] [37] [38]. GSH is essential to combat pathogens growth and their attack to human body including T-lymphocyte proliferation [39] [40], phagocytic activity of polymorphonuclear neutrophils (PMN) and dendritic cells [41]. Most of the basic interactions between acquired and innate immune cells are in the form of peptide antigen presentation representing major histocompatability complex formation. Important role of GSH has been for the first step in antigen degradation and processing is the reduction of disulfide bond which requires [42] [43]. GSH has been shown to alter cytokine expression specifically by enhancement through NAC [28] [44] [45] and $\gamma$-glutamyl cysteine synthase [46]. The specific role of GSH functions in adaptive immune cells is an important phenomenon to understand the correlation between the absence of intracellular glutathione and its reduced ability to remove the microbial infection by host cell.

\section{GSH and Its Effectiveness for Other Viral Infections}

Viral pathophysiology mechanism is reported to be associated with disruption of the redox status of the cell in favor of oxidative stress which results into disturbed function of GSH [47]. Reduced form of the GSH is a major intracellular redox biological molecule that plays a vital role in protecting cells against damage from oxidants [48]. Viral infection studies had shown that oxidative stress and a decreased level of intracellular GSH occurs together in the host cells after infection such as HIV, hepatitis C [49], herpes simplex type 1 [50], Sendai (parainfluenza) virus [51], rhinovirus [52] and influenza virus [53].

A murine model of influenza-A virus infection has shown the loss of reduced GSH in vivo [54]. It has been observed that the virus alone has not been able to show cytopathic effect on the epithelial cells lining of the respiratory tract and complicated pneumonia resulted from infection has not been explained properly [55]. Therefore findings support the hypothesis that the tissue damage may be due to the host itself inflammatory response to the virus and not directly from the virus. It is further suggested that the effector mechanisms involved in the 
removal of pathogens through a complex mechanism where ROS generated by phagocytes participate in the disease [54] [56]. ROS themselves also impart their role to the damaging effect in the lungs cells after viral infection by oxidation of lipids and damaging cell membranes, proteins and nucleic acid [57] or inactivating vital antioxidant enzymes [58]. Further it was also observed a decrease in total GSH, increased GSSG during this disturbed mechanism and apart from this an increased level of malondialdehyde, which is a biomarker of lipid peroxidation [59] in bronchoaleveolar lavage (BAL) fluid from mice infected with influenza virus.

\section{Viral Infection and Cellular Deprivation of GSH}

Intracellular GSH depletion has already been reported in various viral infections through multiple mechanisms. Cellular GSH loss has been reported with Sendai (parainfluenza virus), an RNA virus, where an early leakage of GSH is due to the perturbed cell membrane following the viral interaction [51]. The initial loss of GSH is reported due to the decreased function of enzymes responsible and contributing the maintenance of cellular ions $\left(\mathrm{Na}^{+} / \mathrm{H}^{+}\right)$exchange in the cell membrane. A decrease in the $\mathrm{pH}$ of the cell (acidification) is directly related with the increased number protons $\left(\mathrm{H}^{+}\right)$in the cell, this acidification is associated with the loss of the ion exchange pump. This acidic environment in the cell favors the viral infection and by accelerating the viral fusion process and therefore enhancing the replication and propagation [41] [60] [61].

Secondly deprivation of GSH after viral infection associated with viral replication and infected cells have been found to show a decrease in GSH content and an increase in mixed disulfide complex formation [51]. It supposed that the second expiration of GSH during viral replication is because of the rapid incorporation of cysteine amino acid into the viral gene RNA proteins [50] [62] [63]. There is clear evidence that an increased oxidative state favors the cellular environment for viral replication and it is also observed that the administration of the antioxidant dithiothreitol (DTT) to maintain high GSH levels in the cells resulted in a decrease in virus production. It was speculated that the higher GSH levels can inhibit the formation of mixed disulfides compound and results in the production of inactive virus by inhibiting the folding process of viral proteins [64]. There are well studied reports having evidence that decreasing GSH with a mixed disulfide-forming agent resulted in an increase in viral replication [51].

\section{Viral Infection and Role of Trace Elements}

Malnutrition has shown its impacts on increased susceptibility to various infectious diseases. The malnourished host believed to be susceptible for contagious disease that may results into impaired immune responses, which could influence the immune responses by inducing potential ability to counter the challenges of contagious disease [65]. The trace elements comprises of metals present in cells or in biological fluids at very low concentration join together with vitamins, 
form an enzymes and are essential for proper functioning of almost every physiological processes. They can combine moderately to certain extent to form stable complexes with enzymes, nucleic acids and other biological ligands. They can play as triggering factor or activators to control various biological functions. Several biological functions rely upon dietary micronutrients such as Copper, Zinc and Manganese in superoxide dismutase. Oxidative stress has been shown to be the first mechanism in infection if micronutrients are in deficiency [66]. Trace elements and some of their interactions with biological molecules have been shown to be antiviral in nature by combining with cellular proteins and causing them to be inactive. Some of the trace elements may enhance rigorousness of the other viral infections. Thus trace elements may have an important role in abnormal health conditions caused by viruses [65].

Many components of innate immunity could be influenced by trace elements/micronutrients such as Zinc, Selenium, Iron, Copper etc. Studies has shown that selected micronutrients may play an influential role in modification of oxidants mediated tissue injury and as a results phagocytic cells produce reactive oxygen species in response to defense against infectious diseases. With sufficient micronutrients the injury of the cells participating in innate immunity can be prevented. Natural killer cell functions are reduced if cell is deficient in Zinc, whereas supplement of zinc may enhance their activity. Many cell biochemistry, immunological and physiologically important activities of the body are dependent on trace elements required as micronutrients supplements. It is clearly demonstrated the role of trace elements for efficient function of immune systems include Zinc, Copper, Iron and Selenium. Some studied on animals and human have shown that addition of deficient nutrient to the food can reconstruct immune function and resistance to infection. Zinc and Selenium trace elements have been studies most in this line. Zinc is an important element present in almost every cell. It is associated with the activity of several enzymes [67], support healthy immune system. Sufficient zinc level is necessary for the division of T-cell their maturation and differentiation. The immune system is supposed to be badly affected if zinc deficiency occurs [68]. Zinc may induce the synthesis of metallothionein, sulfhydril rich protein that protect against free radicals [69]. Further, it has been suggested a very important role of zinc metalloprotein to inhibit the transmission of viral disease. Selenium and Copper concentration in erythrocytes can improve the trace element dependant oxidants status [70]. Selenocystein containing protein has been shown to contain selenium as a necessary component that is highly associated with the normal functioning of the cell and can regulate the immune system. Selenium is as integral part of many antioxidant enzymes which are involved into protection of cell against harmful effects of the free radicals. Selenium as a component of selenoprotein has been found to be necessary for proper functioning of macrophages, neutrophils, natural killer cells and T-lymphocytes, also shown to develop resistance against many of the infectious diseases through adjusting the interleukin production 
and therefore reduce pathological conditions such as oxidative stress and severe inflammation [71].

\section{Conclusion}

There is a demand of understanding the redox-regulated intracellular pathways rendered active and manipulated by the virus. Therefore, a new approach is required to inhibit the cell pathways that are responsible for viral replication and to combat the serious health issues. Furthermore, antioxidants possibly interrupt the normal signaling processes that control the usual response to intense infection. The virus-induced oxidative stress through various mechanisms is attributed to the production of proinflammatory cytokines IL-1b and IL-18, which are crucial for host defense to pathogens. Widely used precursor of glutathione such as NAC has been found to reduce the over activation of signaling process implicated in acquired and innate immunity and in restoring the intracellular redox balance as well as effective in controlling viral replication and virus-induced inflammation. Various micronutrients/trace elements have immunomodulatory functions and thus influence the susceptibility of a host to different viral infections. Therefore, it is interesting to evaluate the potential benefit of supplementation of trace elements status as productive means of reducing the danger of contagious diseases. In summary, the biology of redox balance has undergone for much attention that may induce cellular damage to biologically important molecules regulating essential cellular signaling pathways. Although most of the trials worldwide focus on improvement of the clinical conditions, decreasing the virus replication and reduction of mortality rates on trial basis by using the various antimalarial and antiviral drugs. As a therapeutic intervention, the potential of an antioxidant administration strategy and trace elements is very important to overcome the critical health complications. Corona virus denouncement has already added potential threats to human health issues and more research is required in future to understand the underlying biological events for virus outbreaks.

\section{Conflicts of Interest}

The authors declare no conflicts of interest regarding the publication of this paper.

\section{References}

[1] König, R., Stertz, S., Zhou, Y., Inoue, A., Hoffmann, H.H., Bhattacharyya, S., Alamares, J.G., Tscherne, D.M., Ortigoza, M.B. Liang, Y., et al. (2010) Human Host Factors Required for Influenza Virus Replication. Nature, 463, 813-817. https://doi.org/10.1038/nature08699

[2] Nencioni, L., Sgarbanti, R., Amatore, D., Checconi, P., Celestino, I., Limongi, D., Anticoli, S., Palamara, A.T., Garaci, E., et al. (2011) Intracellular Redox Signaling as Therapeutic Target for Novel Antiviral Strategy. Current Pharmaceutical Design, 17, 3898-3904. https://doi.org/10.2174/138161211798357728 
[3] Khomich, O.A., Kochetkov, S.N., Bartosch, B. and Ivanov, A.V. (2018) Redox Biology of Respiratory Viral Infections. Viruses, 10, 392. https://doi.org/10.3390/v10080392

[4] Rahman, I. and MacNee, W. (1996) Role of Oxidants/Antioxidants in Smoking-Induced Airways Diseases. Free Radical Biology and Medicine, 21, 669-681. https://doi.org/10.1016/0891-5849(96)00155-4

[5] Morcillo, E.J., Estera, J. and Cortijo, J. (1999) Oxidative Stress and Pulmonary Inflammation: Pharmacological Intervention with Antioxidants. Pharmacological Research, 40, 393-404. https://doi.org/10.1006/phrs.1999.0549

[6] Taubenberger, J.K. and Morens, D.M. (2008) The Pathology of Influenza Virus Infections. Annual Review of Pathology, 3, 499-522. https://doi.org/10.1146/annurev.pathmechdis.3.121806.154316

[7] Janssen-Heininger, Y.M., Mossman, B.T., Heintz, N.H., Forman, H.J., Kalyanaraman, B., Finkel, T., Stamler, J.S., Rhee, S.G., van der Vliet, A., et al. (2008) Redox-Based Regulation of Signal Transduction: Principles, Pitfalls, and Promises. Free Radical Biology and Medicine, 45, 1-17. https://doi.org/10.1016/j.freeradbiomed.2008.03.011

[8] Rhee, S. (2006) Cell Signaling. $\mathrm{H}_{2} \mathrm{O}_{2}$, a Necessary Evil for Cell Signaling. Science, 312, 1882-1883. https://doi.org/10.1126/science.1130481

[9] Finkel, T. (2012) From Sulfenylation to Sulfhydration: What a Thiolate Needs to Tolerate. Science Signaling, 5, pe10. https://doi.org/10.1126/scisignal.2002943

[10] Wood, Z.A., Poole, L.B. and Karplus, P.A. (2003) Peroxidation Evolution and the Regulation of Hydrogen Peroxide Signaling. Science, 300, 650-653. https://doi.org/10.1126/science.1080405

[11] Pani, G., Colavitti, R., Borrello, S. and Galeotti, T. (2000) Redox Regulation of Lymphocyte Signaling. IUBMB Life, 49, 381-389.

https://doi.org/10.1080/152165400410227

[12] Esposito, F., Ammendola, R., Faraonio, R., Russo, T. and Cimino, F. (2004) Redox Control of Signal Transduction, Gene Expression and Cellular Senescence. Neurochemical Research, 29, 617-628. https://doi.org/10.1023/B:NERE.0000014832.78725.1a

[13] Uhlig, S. and Wendel, A. (1992) The Physiological Consequences of Glutathione Variations. Life Sciences, 51, 1083-1094. https://doi.org/10.1016/0024-3205(92)90509-N

[14] Meister, A. and Anderson, M.E. (1983) Glutathione. Annual Review of Biochemistry, 52, 711-760. https://doi.org/10.1146/annurev.bi.52.070183.003431

[15] Abate, C., Patel, L., Rauscher, F.J. and Curran, T. (1990) Redox Regulation of Fos and Jun DNA-Binding Activity in Vitro. Science, 249, 1157-1161. https://doi.org/10.1126/science.2118682

[16] Schenk, H., Klein, M., Erdbrugger, W., Droge, W. and Schulze-Osthoff, K. (1994) Distinct Effects of Thioredoxin and Antioxidants on the Activation of Transcription Factors NF-kappa B and AP-1. Proceedings of the National Academy of Sciences of the United States of America, 91, 1672-1676. https://doi.org/10.1073/pnas.91.5.1672

[17] Bauer, M. and Bauer, I. (2002) Heme Oxygenase-1: Redox Regulation and Role in the Hepatic Response to Oxidative Stress. Antioxidants \& Redox Signaling, 4, 749-758. https://doi.org/10.1089/152308602760598891

[18] Haddad, J.J. (2002) Oxygen-Sensitive Pro-Inflammatory Cytokines, Apoptosis Signaling and Redox-Responsive Transcription Factors in Development and Pathophysiology. Cytokines, Cellular \& Molecular Therapy, 7, 1-14. 
https://doi.org/10.1080/13684730216401

[19] Kwon, Y.W., Masutani, H., Nakamura, H., Ishii, Y. and Yodoi, J. (2003) Redox Regulation of Cell Growth and Cell Death. Biological Chemistry, 384, 991-996.

https://doi.org/10.1515/BC.2003.111

[20] Wang, J., Chen, Y., Gao, N., Wang, Y., Tian, Y., Wu, J., Zhang, J., Zhu, J., Fan, D., An, J., et al. (2013) Inhibitory Effect of Glutathione on Oxidative Liver Injury Induced by Dengue Virus Serotype 2 Infections in Mice. PLoS ONE, 8, e55407. https://doi.org/10.1371/journal.pone.0055407

[21] Soundravally, R., Sankar, P., Hoti, S.L., Selvaraj, N., Bobby, Z. and Sridhar, M.G. (2008) Oxidative Stress Induced Changes in Plasma Protein Can Be a Predictor of Imminent Severe Dengue Infection. Acta Tropica, 106, 156-161. https://doi.org/10.1016/j.actatropica.2008.03.001

[22] Brennan, F.M., Maini, R.N. and Feldmann, M. (1995) Cytokine Expression in Chronic Inflammatory Disease. British Medical Bulletin, 51, 368-384.

https://doi.org/10.1093/oxfordjournals.bmb.a072967

[23] Rahman, I. and MacNee, W. (1998) Role of Transcription Factors in Inflammatory Lung Diseases. Thorax, 53, 601-612. https://doi.org/10.1136/thx.53.7.601

[24] Verhasselt, V., Vanden Berghe, W., Vanderheyde, N., Willems, F., Haegeman, G. and Goldman, M. (1999) N-acetyl-L-cysteine Inhibits Primary Human T Cell Responses at the Dendritic Cell Level: Association with NF-kappaB Inhibition. The Journal of Immunology, 162, 2569-2574.

[25] Buhl, R., Vogelmeier, C., Critenden, M., Hubbard, R.C., Hoyt Jr., R.F., Wilson, E.M., Cantin, A.M., Crystal, R.G., et al. (1990) Augmentation of Glutathione in the Fluid Lining the Epithelium of the Lower Respiratory Tract by Directly Administering Glutathione Aerosol. Proceedings of the National Academy of Sciences of the United States of America, 87, 4063-4067. https://doi.org/10.1073/pnas.87.11.4063

[26] Strieter, R.M., Kunkel, S.L. and Bone, R.C. (1993) Role of Tumor Necrosis Factor-Alpha in Disease States and Inflammation. Critical Care Medicine, 21, S447-S463. https://doi.org/10.1097/00003246-199310001-00006

[27] Rothstein, J.L., Lint, T.F. and Schreiber, H. (1988) Tumor Necrosis Factor/Cachectin; Induction of Hemorrhagic Necrosis in Normal Tissue Requires the Fifth Component of Complement (C5). Journal of Experimental Medicine, 168, 2007-2021. https://doi.org/10.1084/jem.168.6.2007

[28] Brill, K.J., Li, Q., Larkin, R., Canaday, D.H., Kaplan, D.R., Boom, W.H., Silver, R.F., et al. (2001) Human Natural Killer Cells Mediate Killing of Intracellular Mycobacterium tuberculosis H37Rv via Granule-Independent Mechanisms. Infection and Immunity, 69, 1755-1765. https://doi.org/10.1128/IAI.69.3.1755-1765.2001

[29] Guerra, C., Morris, D., Sipin, A., Kung, S., Franklin, M., Gray, D., Tanzil, M., Guilford, F., Khasawneh, F.T., Venketaraman, V., et al. (2011) Glutathione and Adaptive Immune Responses against Mycobacterium tuberculosis Infection in Healthy and HIV Infected Individuals. PLOS ONE, 6, e28378.

https://doi.org/10.1371/journal.pone.0028378

[30] Guerra, C., Johal, K., Morris, D., Moreno, S., Alvarado, O., Gray, D., Tanzil, M., Pearce, D., Venketaraman, V., et al. (2012) Control of Mycobacterium tuberculosis Growth by Activated Natural Killer Cells. Clinical \& Experimental Immunology, 168, 142-152. https://doi.org/10.1111/j.1365-2249.2011.04552.x

[31] Morris, D., Guerra, C., Donohue, C., Oh, H., Khurasany, M. and Venketaraman, V. (2012) Unveiling the Mechanisms for Decreased Glutathione in Individuals with HIV Infection. Clinical and Developmental Immunology, 2012, Article ID: 734125. 
https://doi.org/10.1155/2012/734125

[32] Green, R.M., Seth, A. and Connell, N.D. (2000) A Peptide Permease Mutant of $M Y$ cobacterium bovis BCG Resistant to the Toxic Peptides Glutathione and S-nitrosoglutathione. Infection and Immunity, 68, 429-436. https://doi.org/10.1128/IAI.68.2.429-436.2000

[33] Seres, T., Knickelbein, R.G., Warshaw, J.B. and Johnston Jr., R.B. (2000) The Phagocytosis-Associated Respiratory Burst in Humanmonocytes Is Associated with Increased Uptake of Glutathione. The Journal of Immunology, 165, 3333-3340. https://doi.org/10.4049/jimmunol.165.6.3333

[34] Venketaraman, V., Dayaram, Y.K., Amin, A.G., Ngo, R., Green, R.M., Talaue, M.T., Mann, J., Connell, N.D., et al. (2003) Role of Glutathione in Macrophage Control of Mycobacteria. Infection and Immunity, 71, 1864-1871.

https://doi.org/10.1128/IAI.71.4.1864-1871.2003

[35] Van Heyningen, T.K., Collins, H.L. and Russell, D.G. (1996) IL-6 Produced by Macrophages Infected with Mycobacterium Species Suppresses T Cell Responses. The Journal of Immunology, 158, 330-337.

[36] Forman, H.J. (2016) Glutathione-From Antioxidant to Post-Translational Modifier. Archives of Biochemistry and Biophysics, 595, 64-67.

https://doi.org/10.1016/j.abb.2015.11.019

[37] Diotallevi, M., Checconi, P., Palamara, A.T., Celestino, I., Coppo, L., Holmgren, A., Abbas, K., Peyrot, F., Mengozzi, M., Ghezzi, P., et al. (2017) Glutathione Fine-Tunes the Innate Immune Response toward Antiviral Pathways in a Macrophage Cell Line Independently of Its Antioxidant Properties. Frontiers in Immunology, 8, 1239.

https://doi.org/10.3389/fimmu.2017.01239

[38] Checconi, P., Limongi, D., Baldelli, S., Ciriolo, M.R., Nencioni, L. and Palamara, A.T. (2019) Role of Glutathionylation in Infection and Inflammation. Nutrients, 11, 1952. https://doi.org/10.3390/nu11081952

[39] Sido, B., Braunstein, J., Breitkreutz, R., Herfarth, C. and Meuer, S.C. (2000) Thiol-Mediated Redox Regulation of Intestinal Lamina Propria T Lymphocytes. Journal of Experimental Medicine, 192, 907-912. https://doi.org/10.1084/jem.192.6.907

[40] Hadzic, T., Li, L., Cheng, N., Walsh, S.A., Spitz, D.R. and Knudson, C.M. (2005) The Role of Low Molecular Weight Thiols in T Lymphocyte Proliferation and IL-2 Secretion. The Journal of Immunology, 175, 7965-7972. https://doi.org/10.4049/jimmunol.175.12.7965

[41] Ozawa, M., Asano, A. and Okada, Y. (1976) Importance of Interpeptide Disulfide Bond in a Viral Glycoprotein with Hemaglutination and Neuraminidase Activities. FEBS Letters, 70, 145-149. https://doi.org/10.1016/0014-5793(76)80745-4

[42] Short, S., Merkel, B.J. and Caffrey McCoy, K.L. (1996) Defective Antigen Processing Correlates with a Low Level of Intracellular Glutathione. European Journal of Immunology, 26, 3015-3020. https://doi.org/10.1002/eji.1830261229

[43] Arunachalam, B., Phan, U.T. and Geuze, H.J. (2000) Enzymatic Reduction of Disulfide Bonds in Lysosomes: Characterization of a Gamma-Interferon-Inducible Lysosomal Thiol Reductase (GILT). Proceedings of the National Academy of Sciences of the United States of America, 97, 745-750. https://doi.org/10.1073/pnas.97.2.745

[44] Venketaraman, V., Millman, A., Salman, M., Swaminathan, S., Goetz, M., Lardizabal, A., Hom, D., Connell, N.D., et al. (2008) Glutathione Levels and Immune Responses in Tuberculosis Patients. Microbial Pathogenesis, 44, 255-261. https://doi.org/10.1016/j.micpath.2007.09.002 
[45] Yan, Z., Garg, S.K. and Banerjee, R. (2010) Regulatory T Cells Interfere with Glutathione Metabolism in Dendritic Cells and T Cells. Journal of Biological Chemistry, 285, 41525-41532. https://doi.org/10.1074/jbc.M110.189944

[46] Ristoff, E.A. (2007) Larsson, Inborn Errors in the Metabolism of Glutathione. Orphanet Journal of Rare Diseases, 2, Article No. 16.

https://doi.org/10.1186/1750-1172-2-16

[47] Meister, A. (1994) Glutathione, Ascorbate, and Cellular Protection. Cancer Research, 54, 1969-1975.

[48] Boya, P., de la Pena, A., Beloqui, O., Larrea, E., Conchillo, M., Castelruiz, Y., Civeira, M.P., Prieto, J., et al. (1999) Antioxidant Status and Glutathione Metabolism in Peripheral Blood Mononuclear Cells from Patients with Chronic Hepatitis C. Journal of Hepatology, 31, 808-814. https://doi.org/10.1016/S0168-8278(99)80281-5

[49] Palamara, A.T., Perno, C.F., Ciriolo, M.R., Dini, L., Balestra, E., D’Agostini, C., Di Francesco, P., Favalli, C., Rotilio, G., Garaci, E., et al. (1995) Evidence for Antiviral Activity of Glutathione: In Vitro Inhibition of Herpes Simplex Virus Type 1 Replication. Antiviral Research, 27, 237-253. https://doi.org/10.1016/0166-3542(95)00008-A

[50] Ciriolo, M.R., Palamara, A.T., Incerpi, S., Lafavia, E., Buè, M.C., De Vito, P., Garaci, E., Rotilio, G., et al. (1997) Loss of GSH, Oxidative Stress and Decrease of Intracellular $\mathrm{pH}$ as Sequential Steps in Viral Infection. Journal of Biological Chemistry, 272, 2700-2708. https://doi.org/10.1074/jbc.272.5.2700

[51] Papi, A., Contoli, M., Gasparini, P., Bristot, L., Edwards, M.R., Chicca, M., Leis, M., Ciaccia, A., Caramori, G., Johnston, S.L., Pinamonti, S., et al. (2008) Role of Xanthine Oxidase Activation and Reduced Glutathione Depletion in Rhinovirus Induction of Inflammation in Respiratory Epithelial Cells. Journal of Biological Chemistry, 283, 28595-28606. https://doi.org/10.1074/jbc.M805766200

[52] Cai, J., Chen, Y., Seth, S., Furukawa, S., Compans, R.W. and Jones, D.P. (2003) Inhibition of Influenza Infection by Glutathione. Free Radical Biology and Medicine, 34, 928-936. https://doi.org/10.1016/S0891-5849(03)00023-6

[53] Hennet, T., Peterhans, E. and Stocker, R. (1992) Alterations in Antioxidant Defences in Lung and Liver of Mice Infected with Influenza A Virus. Journal of General Virology, 73, 39-46. https://doi.org/10.1099/0022-1317-73-1-39

[54] Peterhans, E., Grob, M., Burge, T. and Zanoni, R. (1987) Virus-Induced Formation of Reactive Oxygen Intermediates in Phagocytic Cells. Free Radical Research Communications, 3, 39-46. https://doi.org/10.3109/10715768709069768

[55] Peterhans, E. (1997) Reactive Oxygen Species and Nitric Oxide in Viral Diseases. Biological Trace Element Research, 56, 107-116. https://doi.org/10.1007/BF02778986

[56] Imlay, J.A. and Linn, S. (1988) DNA Damage and Oxygen Radical Toxicity. Science, 240, 1302-1309. https://doi.org/10.1126/science.3287616

[57] Weiss, S.J. (1989) Tissue Destruction by Neutrophils. New England Journal of Medicine, 320, 365-376. https://doi.org/10.1056/NEJM198902093200606

[58] Suliman, H.B., Ryan, L.K., Bishop, L. and Folz, R.J. (2001) Prevention of Influenza-Induced Lung Injury in Mice Overexpressing Extracellular Superoxide Dismutase. The American Journal of Physiology-Lung Cellular and Molecular Physiology, 280, L69-L78. https://doi.org/10.1152/ajplung.2001.280.1.L69

[59] Wiley, D.C. and Skehel, J.J. (1987) The Structure and Function of the Hemagglutinin Membrane Glycoprotein of Influenza Virus. Annual Review of Biochemistry, 56, 365-394. https://doi.org/10.1146/annurev.bi.56.070187.002053 
[60] Sarkar, D.P., Morris, S.J., Eidelman, O., Zimmerberg, J. and Blumenthal, R. (1989) Initial Stages of Influenza Hemagglutinin-Induced Cell Fusion Monitored Simultaneously by Two Fluorescent Events: Cytoplasmic Continuity and Lipid Mixing. Journal of Cell Biology, 109, 113-122. https://doi.org/10.1083/jcb.109.1.113

[61] Perez, L. and Carrasco, L. (1994) Involvement of the Vacuolar H(+)-ATPase in Animal Virus Entry. Journal of General Virology, 75, 2595-2606.

https://doi.org/10.1099/0022-1317-75-10-2595

[62] Tatu, U., Hammond, C. and Helenius, A. (1995) Folding and Oligomerization of Influenza Hemagglutinin in the ER and the Intermediate Compartment. The EMBO Journal, 14, 1340-1348. https://doi.org/10.1002/j.1460-2075.1995.tb07120.x

[63] Sgarbanti, R., Nencioni, L., Amatore, D., Coluccio, P., Fraternale, A., Sale, P., Mammola, C.L., Carpino, G., Gaudio, E., Magnani, M., et al. (2011) Redox Regulation of the Influenza Hemagglutinin Maturation Process: A New Cell-Mediated Strategy for Anti-Influenza Therapy. Antioxidants \& Redox Signaling, 15, 593-606. https://doi.org/10.1089/ars.2010.3512

[64] Kolm-Litty, V., Sauer, U., Nerlich, A., Lehmann, R. and Schleicher, E.D. (1998) High Glucoseinduced Transforming Growth Factor betal Production Is Mediated by Hexosamine Pathway in Porcine Glomerularmesangial Cells. Journal of Clinical Investigation, 101, 160-169. https://doi.org/10.1172/JCI119875

[65] Chaturvedi, U.C., Shrivastava, R. and Upreti, R.K. (2004) Viral Infections and Trace Elements: A Complex Interaction. Current Science, 87, 1536-1554.

[66] Evans, P. and Halliwell, B. (2001) Micronutrients: Oxidant/Antioxidant Status. British Journal of Nutrition (Suppl.), 85, S67-S74. https://doi.org/10.1079/BJN2000296

[67] Sandstead, H.H. (1994) Understanding Zinc: Recent Observations and Interpretations. Journal of Laboratory and Clinical Medicine, 124, 322-327.

[68] Shankar, A.H. and Prasad, A.S. (1998) Zinc and Immune Function: The Biological Basis of Altered Resistance to Infection. American Journal of Clinical Nutrition, 68, 447S-463S. https://doi.org/10.1093/ajcn/68.2.447S

[69] Rostan, E.F., DeBuys, H.V., Madey, D.L. and Pinnell, S.R. (2002) Evidence Supporting Zinc as an Important Antioxidant for Skin. International Journal of Dermatology, 41, 606-611. https://doi.org/10.1046/j.1365-4362.2002.01567.x

[70] Rukgauer, M., Neugebauer, R.J. and Plecko, T. (2001) The Relation between Selenium, Zinc and Copper Concentration and the Trace Element Dependent Antioxidative Status. Journal of Trace Elements in Medicine and Biology, 15, 73-78. https://doi.org/10.1016/S0946-672X(01)80046-8

[71] Arthur, J.R., McKenzie, R.C. and Beckett, G.J. (2003) Selenium in the Immune System. Journal of Nutrition (Suppl.), 133, 1457S-1459S.

https://doi.org/10.1093/jn/133.5.1457S 